\title{
Biological Activity of Sumilarv 0.5G against Anopheles gambiae sensu stricto and Anopheles arabiensis in Northern Tanzania
}

\author{
Eliningaya J. Kweka, ${ }^{a, b}$ Aneth M. Mahande, ${ }^{c}$ Shandala Msangi, ${ }^{b}$ Subira Sayumwe, ${ }^{b}$ Johnson O. Ouma, \\ Violet Temba, ${ }^{\text {b Lucile J. Lyaruu, }{ }^{\text {b }} \text { Yousif E. Himeidand }}$ \\ aDepartment of Medical Parasitology and Entomology, Catholic University of Health and Allied Sciences, Mwanza, Tanzania; ${ }^{b}$ Division of Livestock and Human \\ Disease Vector Control, Tropical Pesticides Research Institute, Arusha, Tanzania; 'Mabogini Field Station, Tropical Pesticides Research Institute, Moshi, Tanzania; \\ 'Africa Technical Research Centre, Vector Health International, Arusha, Tanzania \\ Correspondence to Eliningaya J. Kweka (eliningaya.kweka@tpri.go.tz)
}

\begin{abstract}
Background: Sumilarv 0.5G (Sumitomo Chemical Co., Ltd., Tokyo, Japan) is a granular insecticide developed for the control of mosquito and fly aquatic stages. The active ingredient is pyriproxyfen (4-phenoxyphenyl (RS)-2-(2 - pyridyloxy) propyl ether), a juvenile hormone analogue that acts as an insect growth regulator. Sumilarv $0.5 \mathrm{G}$ functions by inhibition of adult emergence from pupae. In this study, the Tropical Pesticides Research Institute in Tanzania carried out laboratory, semifield, and full-field evaluation on a new candidate of pupicide, Sumilarv 0.5G. The present study, therefore, sought to test the bioefficacy of Sumilarv 0.5G in laboratory, semifield, and full-field conditions in Mabogini, northern Tanzania.

Methods: Standard World Health Organization laboratory bioefficacy evaluations of Sumilarv 0.5G and untreated microcosms were prepared and monitored for inhibition of the larvae introduced to the habitats, while field plots were monitored for 5 weeks after the introduction of Sumilarv $0.5 \mathrm{G}$ using manufacturer-recommended doses.

Results: Sumilarv $0.5 \mathrm{G}$ biolarvicide was highly efficacious in its pupicidal effect, with an adult emergence inhibition rate of up to $90 \%$ in all conditions. In both laboratory and semifield experiments, the emergence inhibition was dose-dependent, with the lowest adult emergence being recorded in association with the highest Sumilarv $0.5 \mathrm{G}$ dose of $0.03 \mathrm{ppm}$ of active ingredient. Under field conditions, the application rate recommended by the manufacturer $-5 \mathrm{mg}$ ai per $\mathrm{m}^{2}-$ reduced the adult emergence rate by $90 \%$ to $96 \%$ for up to 5 weeks.

Conclusion: We demonstrated the long-lasting biological activity of Sumilarv $0.5 \mathrm{G}$ under field conditions. Notably, the field efficacy was attained using the recommended dose of $5 \mathrm{mg} \mathrm{per} \mathrm{m}^{2}$, thus making it economical to apply this product, which is capable of inhibiting mosquito productivity in natural habitats for longer periods than achieved by existing products, the efficacy of which is usually about 1 week.
\end{abstract}

\section{INTRODUCTION}

$\mathbf{I}^{\mathrm{n}}$ $\mathrm{n}$ Africa, the main malaria vectors are members of Anopheles gambiae sibling species complex and the Anopheles funestus complex. ${ }^{1,2}$ The An. gambiae complex consists of An. gambiae sensu stricto (s.s.), Anopheles arabiensis, Anopheles merus, Anopheles melus, Anopheles bambwae, Anopheles colluzzii, and Anopheles ahmaricus. ${ }^{1,2}$ The An. funestus complex vectors are An. funestus s.s., Anopheles leesoni, Anopheles rivulorum, and Anopheles vaneedeni. ${ }^{3-8}$ The main frontline malaria vector control tools are long-lasting insecticidal nets (LLINs) and indoor residual spraying (IRS). ${ }^{9}$ Insecticide resistance has emerged as an urgent threat to these tools ${ }^{10-12}$ that requires alternative or complementary solutions. Larval source management (LSM) is of paramount importance in the fight against malaria, through vector control, to complement LLINs and IRS. Larval control is a new avenue which, if effectively implemented, can have an impact on malaria epidemiology. ${ }^{13,14}$ LSM has been shown to be more effective when combined with other tools that target adult vectors. ${ }^{14,15}$ Insecticide resistance among disease vectors is achieved via a variety of mechanisms at different vector developmental stages, ${ }^{16}$ but the main advantage of LSM is that it targets the immobile immature stages of mosquito vectors, thus controlling both outdoor and indoor resting and biting vectors. ${ }^{14,17}$

Commercially available chemical and microbial larvicides are highly effective for short-lasting control of the aquatic stages of the main malaria vectors. ${ }^{13,14,18-20}$ The major challenge of existing biolarvicides is their short duration of activity in environmental conditions, 


\section{FIGURE 1. The Irrigated Rice Fields}

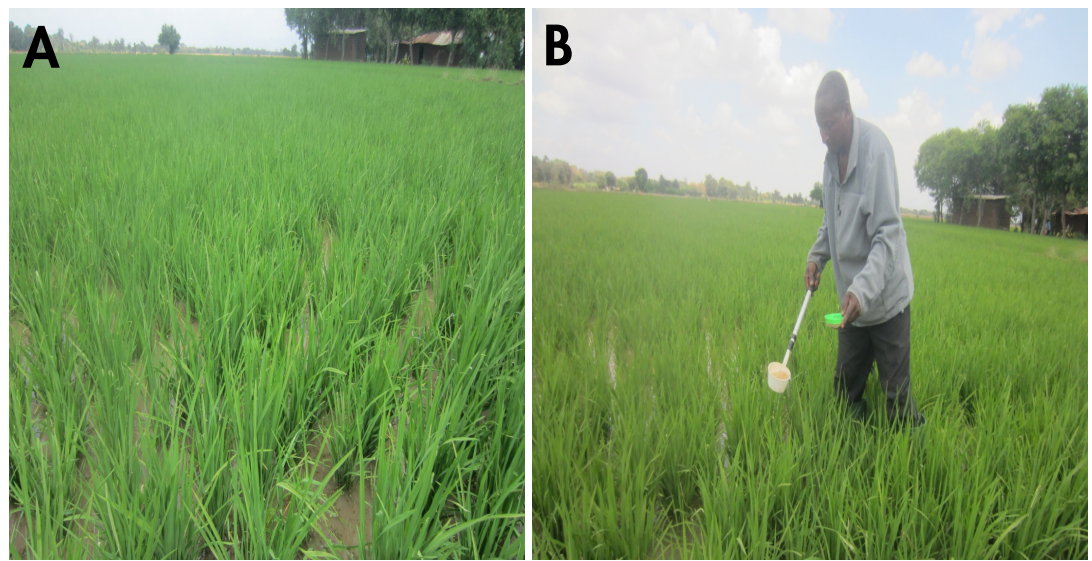

(A) During site selection and (B) during larvae density estimation

which means that they require weekly reapplication. ${ }^{18,21}$ Labour and larvicide supply are the major costs associated with large-scale vector management, which aims to reduce costs by maximising the reapplication intervals. ${ }^{22}$ Also, the toxicity of larvicides to untargeted aquatic insects limits the practicality of regular larvicide programmes. ${ }^{23}$

Sumilarv 0.5G (Sumitomo Chemical Co., Ltd., Tokyo, Japan) is a granular insecticide that was developed to control the pupal stages of mosquitoes and flies. ${ }^{24-27}$ The active ingredient is pyriproxyfen (4-phenoxyphenyl (RS)-2-(2-pyridyloxy) propyl ether), a juvenile hormone analogue that acts as an insect growth regulator. ${ }^{28}$ Pyriproxyfen generally inhibits the adult emergence of target insects species..$^{29,30}$

However, pyriproxyfen causes delayed effects on reproduction among female adult mosquitoes exposed to sublethal doses at the larval ${ }^{31}$ or adult stage. ${ }^{32,33}$ Sumilarv 0.5G has exceptional residual activity of up to more than 1 month for the control of mosquito species in their natural breeding sites. ${ }^{30,33,34}$ Furthermore, pyriproxyfen has been evaluated as a safe insecticide for application in drinking water, ${ }^{35}$ with limited impact on utargeted aquatic insects and the environment. ${ }^{36,37}$ Nevertheless, Sumilarv 0.5G has never been evaluated for the control of An. arabiensis, the major malaria vector in Tanzania.

This study aimed to evaluate the efficacy of Sumilarv 0.5G as a pupicide against An. gambiae s.s. in laboratory and semifield conditions, and against An. arabiensis under field conditions.

\section{METHODS}

\section{Study design}

This was laboratory and field experimental study.

\section{Sumilarv 0.5G Formulation}

Sumilarv 0.5G was applied only to mosquito breeding habitats that did not drain into natural water bodies. According to the manufacturer's instructions, the amount of Sumilarv $0.5 \mathrm{G}$ applied was determined by the volume of water in the respective habitats (width $\times$ length $\times$ depth), based on a target concentration of 0.01 to $0.05 \mathrm{ppm}$ of active ingredient (ai) or (0.2-1.0 oz/100 ft $\left.\mathrm{ft}^{3}\right)$. The targeted habitats were temporary or permanent water holding sites amenable to treatment: ornamental ponds, fountains, cesspools, abandoned swimming pools, gutters, construction site depressions, septic tanks, flooded basements, gutters, animal waste lagoons, livestock runoff lagoons, sewers, sewage effluent, tire tracks, waste water impoundments associated with organic pollutants and industrial run off, waste water and settling ponds, and vegetation-choked phosphate pits. Other potentially treatable sites include natural and artificial water holding containers: hollow trees and tree holes, potted plants, bird baths, tire dumps, landfills, rain barrels, flooded roof tops, flower pots, buckets, salvage yards, abandoned vehicles, vehicle impounds, and junkyards. The targeted mosquito species for Sumilarv 0.5G are Aedes aegypti, Aedes albopictus, Aedes vexans, anophelines, Culex pipiens, Culex quinquefasciatus, Culex tarsalis, and Culex restuans. 


\section{FIGURE 2. Percentage Emergence of Anopheles gambiae sensu stricto in Laboratory Trials for} Different Concentrations

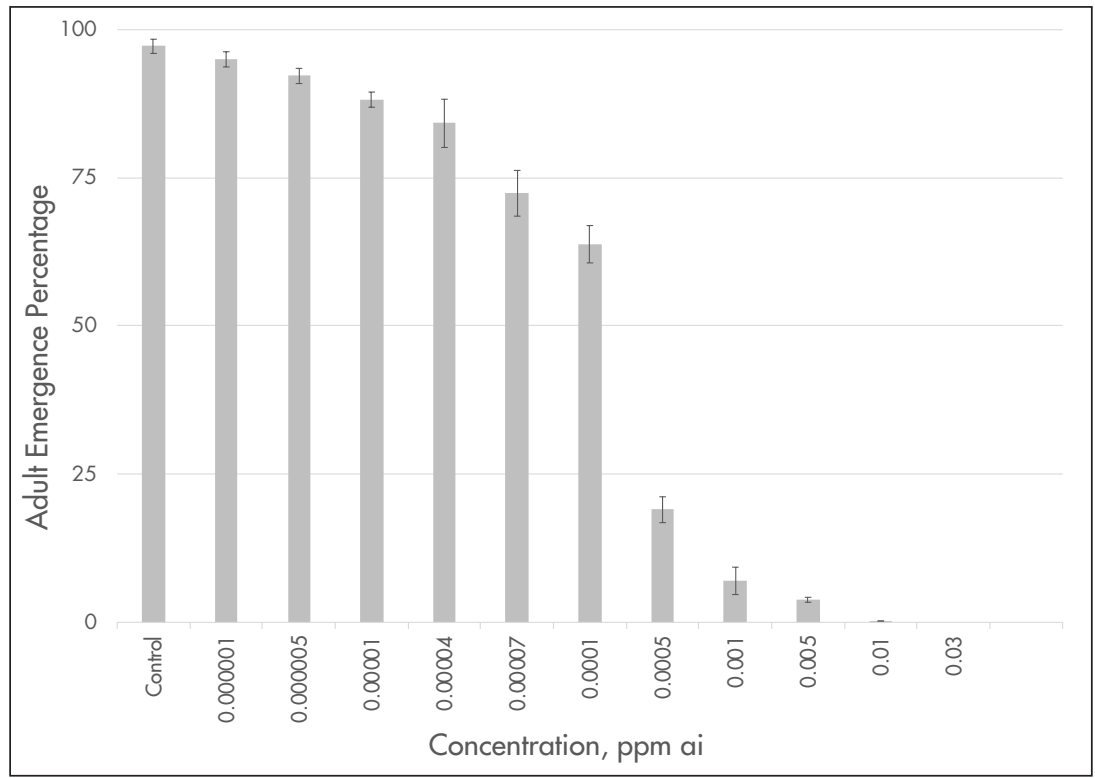

\section{Mosquito Rearing}

Mosquitoes originated from a colony of An. gambiae s.s., established in Kisumu, Kenya, in 1992, and were reared at the Tropical Pesticides Research Institute TPRI. The laboratory larval rearing of protocol is described elsewhere. ${ }^{38,39}$ In the insectary, larvae were fed TetraMin (Spectrum Brands Pet, Blacksburg, VA, USA) fish food at rate of $0.003 \mathrm{~g} /$ larva. Third instar larvae were used for trials, as recommended by the World Health Organization protocol. ${ }^{40}$ The photo phase in the insectary was 12 light:12 darkness, with a temperature of $27^{\circ} \mathrm{C} \pm 2{ }^{\circ} \mathrm{C}$ and a relative humidity of $78 \% \pm 2 \%$.

\section{Dose-Response Bioassays}

Experiments were done in the laboratory and in semifield conditions - experiments conducted in controlled conditions outside the laboratory but with restricted interaction with nature. ${ }^{41}$ Before the dose-response experiments, a range-finding test was implemented by exposing test larvae to a wide range of test concentrations and a control. This was used to find the activity range of the insecticide for tested species.

A range of concentrations between 10 ppm ai and $1.0 \times$ $10^{-7} \mathrm{ppm}$ ai were tested. After determining the emergence inhibition of the larvae in a broader range, concentrations causing emergence inhibition of between $10 \%$ and $95 \%$ were chosen and used in dose-response bioassays. ${ }^{40}$ Fifteen serial dilutions were made, and the best 11 doses causing emergence inhibition for use in laboratory and semifield trials were selected. A stock solution was prepared by grinding the granular formulation into a fine powder, following the procedure described Sihuincha et al. ${ }^{33}$ Using a pestle and mortar, 5 g of SumiLarv 0.5 G (25 mg ai) was ground and added to 500 $\mathrm{ml}$ of unchlorinated tap water. This produced a stock solution of 10,000 ppm SumiLarv 0.5G (50 ppm ai). The top of the vial was covered with aluminium foil, and the solution was left to agitate for 1 hour on a shaker. The mixture was left overnight to allow the active ingredient to be released into the solution. The next morning, the mixture was again agitated on a shaker for 30 minutes to prepare a homogenous mixture, as some of the inert ingredients of the formulation - potentially still containing some active ingredient - had settled overnight. Serial dilutions were made immediately after shaking in unchlorinated tap water to produce the test concentrations.

The laboratory-reared colony of An. gambiae s.s. was evaluated against different concentrations of Sumilarv 0.5G. Each test concentration and a control were replicated 6 times, and $200 \mathrm{ml}$ of each test solution was set up in $300 \mathrm{ml}$ glass bowls. The test was repeated 3 times for each concentration. Separate batches of 25 insectary-reared third instar larvae of test species were introduced into each test concentration and the control.

Larvae were fed with TetraMin (Spectrum Brands) fish food only when the experiments were monitored for more than 24 hours. Bowls were covered with netting to prevent any emerging adults from escaping. The pupae were monitored until emergence or death. The number of dead larvae, pupae, and emerging adults were recorded until the end of the experiment, when all pupae had emerged or died. Live 
FIGURE 3. Percentage Emergence of Anopheles gambiae sensu stricto in Semifield Trials for Different Concentrations

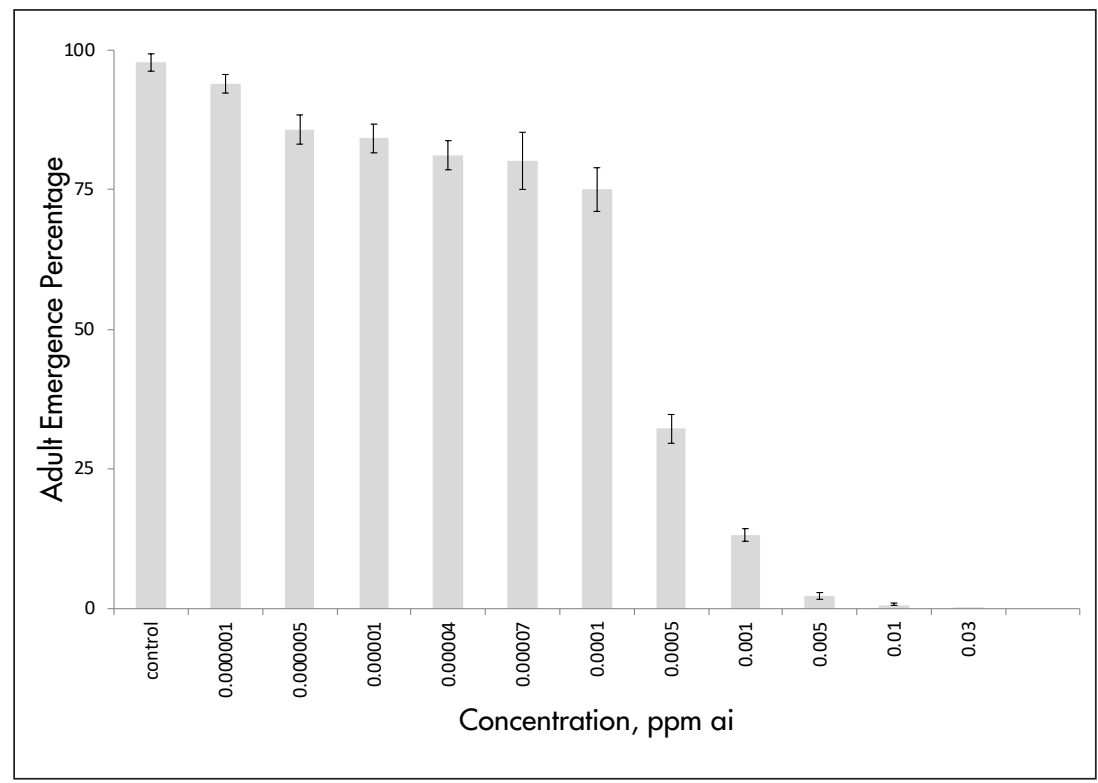

pupae from each bowl were transferred into a separate bowl containing $20 \mathrm{ml}$ of water from the habitats. These bowls were covered with netting for monitoring adult emergence. Separate pipettes were used to collect pupae from treated and control bowls to avoid cross-contamination.

\section{Semifield Studies}

Semifield trials were carried out in an open field with artificial microcosms. ${ }^{40,42}$ Six artificial microcosms were made up using small washing basins (diameter, $21.5 \mathrm{~cm}$; depth, $10 \mathrm{~cm}$ ) filled with $1 \mathrm{~kg}$ of soil and 1,500 $\mathrm{ml}$ of water to resemble a natural larval habitat. Microcosms were paired between treatments and controls at $3 \mathrm{~m}$ intervals. Monitoring of the microcosms was conducted daily until the first pupa was observed, then monitoring was conducted twice a day. All pupae were collected with some water from each microcosm. Batches of 25 insectary-reared third instar larvae were introduced into each microcosm.

\section{Field Trials}

Two pairs of rice plots were selected for the field trials, with larval abundance evaluated before treatments (Figure 1). Two were control plots, and the other 2 were treatment plots. The plots measured $70 \mathrm{~m} \times 20 \mathrm{~m}$. Larvae were sampled 3 times per week (Monday, Wednesday, and Friday) for 5 weeks. All collected control and treatment pupae were kept in labelled paper bowls and monitored for adult emergence. The effect of Sumilarv 0.5G was measured as adult emergence inhibition in all treated plots, while for the control, emergence inhibition was considered as natural mortality.

\section{Parameters Measured}

The percent inhibition of adult emergence (\%IE) was calculated following the World Health Organization guideline, ${ }^{40}$ using the following formula:

$$
\begin{aligned}
& \text { IE }(\%)=100-(\mathrm{T} \times 100 / \mathrm{C}) \\
& \text { Where, } \\
& \mathrm{T}=\text { percentage survival or emergence in treated } \\
& \quad \text { batches } \\
& \mathrm{C}=\text { percentage survival or emergence in control } \\
& \quad \text { batches }
\end{aligned}
$$

\section{Data Analysis}

Data were analysed using IBM SPSS Statistics version 25 (IBM Corp., Armonk, NY, USA). Descriptive statistics were deployed for data analysis to obtain the confidence intervals and mean differences. Excel (Microsoft Corp., Redmond, WA, USA) spreadsheets were used to calculate percentage inhibition of larvae. The comparison between treatment and control was done using paired samples t-tests. Probit analysis was used to calculate the $\mathrm{LC}_{50}$ and $\mathrm{LC}_{95}$. $P$ values less than .05 were considered statistically significant. 
FIGURE 4. Percentage Emergence of Anopheles gambiae sensu stricto in the Field Trials for 5 Weeks After a Single Treatment

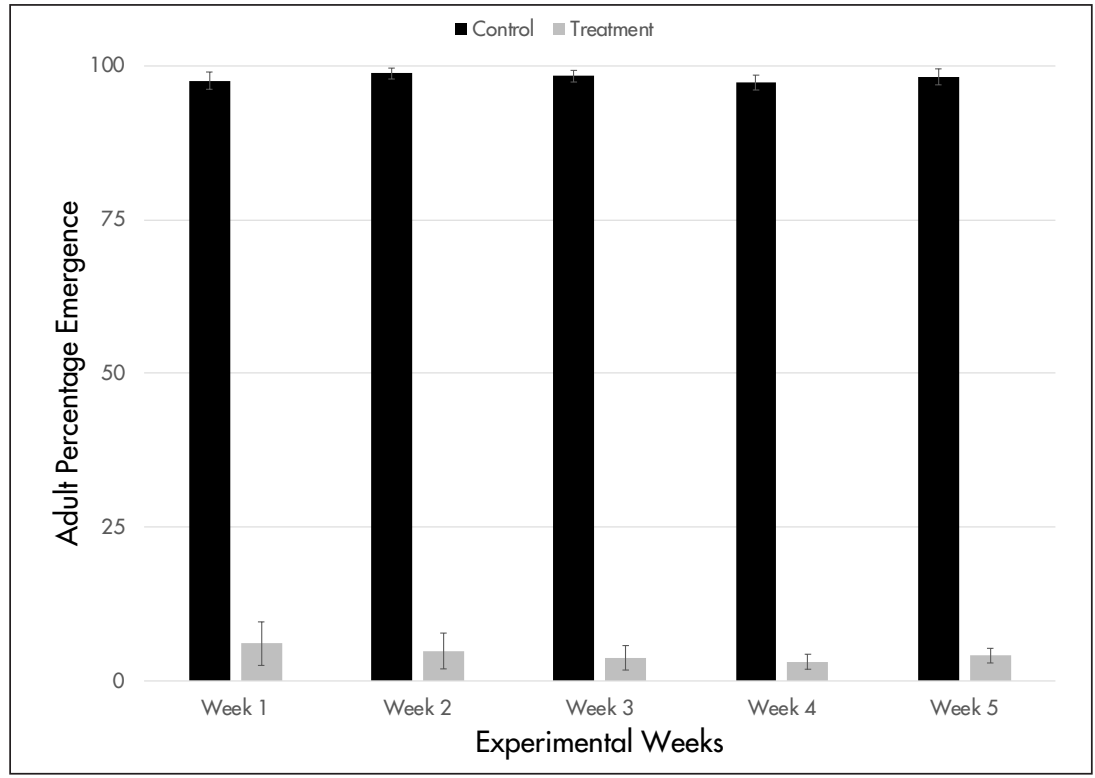

\section{Ethical Considerations}

Approval for this study was granted by the Tanzania Pesticides registrar's office (experimental permit number 2310, issued in 2015).

\section{RESULTS}

\section{Laboratory Trials}

A series of doses were evaluated, and those with emergence inhibition effects were considered for laboratory trials. Selected trial doses ranged from $10^{-6}$ to $0.03 \mathrm{ppm}$ ai. Percentage inhibition was dose-dependent (Figure 2). The dose of 0.03 ppm ai caused $100 \%$ emergence inhibition. The percentage inhibition among treatment doses was statistically significant $(\mathrm{df}=11, \mathrm{~F}=242.9, P<.001)$.

\section{Semifield Trials}

Similar results to those observed in laboratory studies were found in the semifield experiments. Emergency inhibition was dose-dependent, and the highest inhibition levels resulted from the highest doses (Figure 3). Inhibition percentage was statistically different between the groups, with more adult emergence observed at lower doses ( $\mathrm{df}=11, \mathrm{~F}=367.86$, $P<.001)$.

\section{Field Trials}

In the first week of sampling after the plots were treated, the emergence rate for pupae differed significantly between treated and control plots, with more adults emerging from the pupae sampled in the control than the treated plot arms $(\mathrm{df}=4, \mathrm{t}=74.1, P<.001)$. The same was observed in weeks 2 $(\mathrm{df}=4, \mathrm{t}=70.5, \mathrm{P}<.001), 3(\mathrm{df}=4, \mathrm{t}=70.5, P<.001), 4(\mathrm{df}=4, \mathrm{t}=69.7$, $P<.001)$, and $5(\mathrm{df}=4, \mathrm{t}=81.1, P<.001)$, as shown in Figure 4.

\section{DISCUSSION}

Our findings shown that wild An. arabiensis and laboratory An.gambiae s.s. populations had similar responses to Sumilarv $0.5 \mathrm{G}$ under different environmental conditions. Similar findings were presented by a study conducted in Kenya by Mbare et al. ${ }^{43}$ Sumilarv $0.5 \mathrm{G}$ inhibited over $90 \%$ of the total adult emergence over a period of 5 weeks in irrigated rice fields at an application rate of $5 \mathrm{mg}$ ai per $\mathrm{m}^{2}$. This level of inhibition is consistent with observations of a study targeting the control of An.gambiae sensu lato (s.l.) in Kenya, where a concentration of 0.003 ppm pyriproxyfen was enough to completely inhibit emergence for up to 1 month. ${ }^{43}$ In the present study, however, weekly emergence rates remained low for up to 5 weeks, even at the lower doses. Weekly emergence inhibition was frequently higher than $90 \%$, the threshold recommended by the World Health Organization Pesticide Evaluation Scheme for the successful control of immature mosquito stages. ${ }^{40} \mathrm{Ap}$ plication rates in field conditions were increased up to several times the minimum dose instructed by the manufacturer to obtain sufficient control under field conditions. ${ }^{28}$ The findings were consistent with those observed in previous studies. ${ }^{40,44}$ The higher dose of $5 \mathrm{mg}$ ai per $\mathrm{m}^{2}$ in field conditions inhibited over $80 \%$ of adult emergence for 5 weeks. 
Further field tests to establish the optimum dose for operational control in a variety of different habitats are necessary. However, based on the results presented in this study, it is likely that the optimum dose lies between the doses tested here. This concurs with the maximum dose recommended by the manufacturer $(0.05 \mathrm{ppm}$ ai) for field operational control of anopheline mosquito species. ${ }^{28}$ Kawada et al. ${ }^{45}$ previously found emergence inhibition for An. gambiae to be 4 times less than the level found in the present study. The same dose for An. gambiae, however, was found to be in the range recommended for culicine and Aedes species. ${ }^{46,47}$ The observed differences in these studies were attributed to factors such as differences in container types and pyriproxyfen formulations. ${ }^{34,45}$ The study by Kawada et al. ${ }^{45}$ used an emulsifiable concentrate (5\%) formulation, while the present study used a granular formulation. Moreover, in the present study, the plastic bowls used during the bioassays were found to have retained high larvicide amounts leading to a higher residual effect relative to the aluminium bowls used by Kawada et al. ${ }^{45}$ Plastic materials are known to retain substantial amounts of active ingredient and to release it slowly, which could explain the higher emergence inhibition found in this study at all doses used. ${ }^{36,37,48}$ Our experiments have shown that Sumilarv $0.5 \mathrm{G}$ is effective at low active ingredient concentrations. The required concentration of pyriproxyfen is substantially lower than that of other microbial agents used as larvicides. ${ }^{19}$ A previous study on culicine mosquitoes also demonstrated that pyriproxyfen operates effectively at very low concentrations. ${ }^{49}$ The efficacy of lower concentrations will lower the operational costs for larvicide programmes that use Sumilarv $0.5 \mathrm{G}^{22}$ The observed residual impact on An. arabiensis emergence rates was similar to what was found in previous studies on other mosquito species. . $^{34,46}$

In previous studies under field conditions, Sumilarv $0.5 \mathrm{G}$ at $0.02 \mathrm{ppm}$ ai and $0.05 \mathrm{ppm}$ ai effected complete emergence inhibition for 6 weeks for Anopheles quadrimaculatus, Culex nigripalpus, Aedes taeniorhynchus, Ae. albopictus, and Ae. aegypti. ${ }^{50}$ This granular formulation is released and produces its effects relatively slowly compared to other biolarvicides, exhibiting extended residual effects, particularly when applied to mosquito breeding containers. It was very effective against Aedes larvae even when the habitats where flushed with untreated water. ${ }^{34}$ In Sri Lanka, a single dose of $0.1 \mathrm{mg} / \mathrm{l}$ was shown to be sufficient for six months against anopheline malaria vectors in pots and small pits, meaning that 2 applications per annum were sufficient. ${ }^{30}$ In Peru, it was observed that $0.003 \mathrm{~g}$ ai pyriproxyfen $/ \mathrm{m}^{2}$ was sufficient to extend emergence inhibition for 5 months in water tanks housing Ae. aegypti. 33,51

Overall, it can be concluded from previous and our own study that the efficacy and residual activity of different pyriproxyfen-containing products depends on the formulation, dose, habitat types, and vector species. ${ }^{36,46}$

We did not observe that the efficacy of Sumilarv $0.5 \mathrm{G}$ is reduced in turbid water, as reported by Mbare et al. ${ }^{43}$ Some of the turbidity observed in that study might have been due to algae and bacteria growing in the established habitats. It is possible that the debris absorbed some of the active ingredients of the Sumilarv 0.5G, reducing its efficacy. ${ }^{52}$ Debris in aquatic habitats is an important parameter that is often associated with the abundance, development, and survival of An. gambiae s.l. larvae. ${ }^{42,53,54}$ In the recent past, anopheline larvae have been found to exploit aquatic habitats with varying degrees of water turbidity and $\mathrm{pH}$, from sunlit and ephemeral to permanent, large water bodies in both urban and rural areas..$^{54-56}$ Debris and other decaying materials provide mosquitoes with food particles that enhance their aquatic survival, thus increasing adult emergence from turbid water bodies. ${ }^{42,53,54,57,58}$ This condition in natural habitats needs to be considered and monitored in field operations for the effective control of aquatic stages. ${ }^{40}$ At $5 \mathrm{mg}$ ai per $\mathrm{m}^{2}$, reproduction by female mosquitoes declined by over $90 \%$ as a consequence of the sublethal effect of Sumilarv 0.5G on emergence for 5 weeks. Similar effects of pyriproxyfen have been shown for Anopheles, Aedes and Culex species in both laboratory and field conditions. ${ }^{30,31,33,59}$ Another effect is to suppress the viability of eggs, thus reducing emergence rates and subsequently reducing intervention costs. The outcome of stress caused by growth regulators is known to affect the adult sex ratio and reduce blood feeding ability. ${ }^{60}$ The same phenomenon is observed among adult mosquitoes exposed to pyriproxyfen. ${ }^{32}$ Insect growth regulators have also been found to suppress ovarian and egg development. ${ }^{61,62}$ Caution should be taken when considering the continuous use of pyriproxyfen, as resistance might develop, as has occurred with other insecticides. ${ }^{63-66}$ Examining the population of insects surviving after exposure for tolerance against pyriproxyfen must be built into malaria vector control strategies.

\section{CONCLUSION}

We have shown that An. arabiensis and An. gambiae s.s. are highly susceptible to Sumilarv $0.5 \mathrm{G}$ at low doses. This product would, therefore, be useful for targeting productive natural habitats of malaria vectors and help control wild mosquito populations. Such reduction in population size can happen within a relatively short period, as this study has shown that Sumilarv 0.5G significantly inhibits adult emergence and egg viability. We recommend further studies to better understand and standardize re-treatment intervals in both dry and rainy seasons.

Acknowledgements: We wish to thank the technicians at the Tropical Pesticides Research Institute, field officers, and the lower Moshi community members who participated in data generation and collection.

This study was funded by the company that manufactures Sumilarv 0.5G, Sumitomo Chemical Co., Ltd., of Tokyo, Japan. The funder had no role in data collection, data analysis, results interpretation, or the conclusions derived from this study. 


\section{REFERENCES}

1. Coetzee M, Craig M, le Sueur D. Distribution of African malaria mosquitoes belonging to the Anopheles gambiae complex. Parasitol Today. 2000;16(2):74-77. CrossRef. Medline

2. Coetzee M, Hunt RH, Wilkerson R, Della Torre A, Coulibaly MB, Besansky NJ. Anopheles coluzzii and Anopheles amharicus, new members of the Anopheles gambiae complex. Zootaxa. 2013;3619(3):246-274. CrossRef. Medline

3. Derua YA, Alifrangis M, Magesa SM, Kisinza WN, Simonsen PE. Sibling species of the Anopheles funestus group, and their infection with malaria and lymphatic filarial parasites, in archived and newly collected specimens from northeastern Tanzania. Malaria J. 2015;14:104. CrossRef. Medline

4. Kweka EJ, Mahande A, Nkya W, et al. Vector species composition and malaria infectivity rates in Mkuzi, Muheza District, north-eastern Tanzania. Tanzan J Health Res. 2008;10(1):46-49. CrossRef

5. Kweka EJ, Kamau L, Munga S, Lee MC, Githeko AK, Yan G. A first report of Anopheles funestus sibling species in western Kenya highlands. Acta Trop. 2013;128(1):158-161. CrossRef. Medline

6. Kawada H, Dida GO, Sonye G, Njenga SM, Mwandawiro C, Minakawa N Reconsideration of Anopheles rivulorum as a vector of Plasmodium falciparum in western Kenya: some evidence from biting time, blood preference, sporozoite positive rate, and pyrethroid resistance. Parasit Vectors. 2012;5:230. CrossRef. Medline

7. Mboera LEG, Magesa SM. The rise and fall of malarial sporozoite rates in Anopheles gambiae s.l. and An. funestus in north-eastern Tanzania, between 1934 and 1999. Ann Trop Med Parasitol. 2001 ;95(4):325-330. CrossRef. Medline

8. Ogola EO, Chepkorir E, Sang R, Tchouassi DP. A previously unreported potential malaria vector in a dry ecology of Kenya. Parasit Vectors. 2019;12:80 CrossRef. Medline

9. World Health Organization (WHO). World Malaria Report 2018. Geneva: WHO;2018. https://www.who.int/malaria/publications/world-malaria-report-2018/en/. Accessed 21 March 2019.

10. Nnko EJ, Kihamia C, Tenu F, Premii Z, Kweka EJ. Insecticide use pattern and phenotypic susceptibility of Anopheles gambiae sensu lato to commonly used insecticides in Lower Moshi, northern Tanzania. BMC Res Notes. 2017;10:443. CrossRef. Medline

11. Mbepera $S, N$ kwengulila $G$, Peter $R$, et al. The influence of age on insecticide susceptibility of Anopheles arabiensis during dry and rainy seasons in rice irrigation schemes of Northern Tanzania. Malaria J. 2017;16:364. CrossRef. Medline

12. Wanjala CL, Kweka EJ. Malaria vectors insecticides resistance in different agroecosystems in western Kenya. Front Public Health. 2018;6:55. CrossRef. Medline

13. Fillinger $U$, Lindsay SW. Suppression of exposure to malaria vectors by an order of magnitude using microbial larvicides in rural Kenya. Trop Med Int Health. 2006;11(11):1629-1642. CrossRef. Medline

14. Fillinger U, Ndenga B, Githeko A, Lindsay SW. Integrated malaria vector control with microbial larvicides and insecticide-treated nets in western Kenya: a controlled trial. Bull World Health Organ. 2009;87(9):655-665. Medline

15. Geissbühler Y, Kannady K, Chaki PP, et al. Microbial larvicide application by a large-scale, community-based program reduces malaria infection prevalence in urban Dar Es Salaam, Tanzania. PLoS ONE. 2009;4(3):e5107. CrossRef. Medline

16. Matowo J, Kitau J, Kaaya R, et al. Trends in the selection of insecticide resistance in Anopheles gambiae s.l. mosquitoes in northwest Tanzania during a community randomized trial of longlasting insecticidal nets and indoor residual spraying. Med Vet Entomol. 2015;29(1):51-59. CrossRef. Medline

17. Fillinger $U$, Lindsay $S$. Larval source management for malaria control in Africa: myths and reality. Malaria J. 2011;10:353. CrossRef. Medline

18. Fillinger $U$, Kannady K, William G, et al. A tool box for operational mosquito larval control: preliminary results and early lessons from the Urban Malaria Control Programme in Dar es Salaam, Tanzania. Malaria J. 2008;7(1):20. CrossRef. Medline

19. Fillinger U, Knols BGJ, Becker N. Efficacy and efficiency of new Bacillus thuringiensis var. israelensis and Bacillus sphaericus formulations against Afrotropical anophelines in Western Kenya. Trop Med Int Health. 2003;8(1):37-47. CrossRef. Medline
20. Shililu J, Mbogo C, Ghebremeskel T, Githure J, Novak R. Mosquito larval habitats in a semiarid ecosystem in eritrea: Impact of larval habitat management on Anopheles arabiensis population. American J Trop Med Hyg. 2007;76(1):103-110. Medline

21. Skovmand O, Ouedraogo TDA, Sanogo E, Samuelsen H, Toé LP, Baldet T. Impact of slow-release Bacillus sphaericus granules on mosquito populations followed in a tropical urban environment. J Med Entomol. 2009;46(1):67-76. Medline

22. Worrall E, Fillinger U. Large-scale use of mosquito larval source management for malaria control in Africa: a cost analysis. Malaria J. $2011 ; 10: 338$. CrossRef. Medline

23. Fortin MG, Morrison NA, Verma DP. Nodulin-26, a peribacteroid membrane nodulin is expressed independently of the development of the peribacteroid compartment. Nucleic Acids Res. 1987;15(2):813-824. Medline

24. Webb G, Miller P, Peters B. Pyriproxyfen for the control of Australian saltmarsh mosquito, Aedes vigilax. J Am Mosq Control Assoc. 2012;28(1):50-53. CrossRef. Medline

25. Invest J, Lucas J. Pyriproxyfen as a mosquito larvicide. In: Robinson WH, Bajomi D, eds. Proceedings of the Sixth International Conference on Urban Pests. Veszprém, Hungary: OOK-Press Kft; 2008. https://pdfs.semanticscholar.org/0ecc/1 aba6c3110d2078eeb8d43cc64b19ef0ac64.pdf. Accessed 21 March 2019.

26. Lindsay TC, Jawara M, D'Alessandro U, Pinder $M$, Lindsay SW. Preliminary studies developing methods for the control of Chrysomya putoria, the African latrine fly, in pit latrines in The Gambia. Trop Med Int Health. 2013;18(2):159165. CrossRef. Medline

27. Geden CJ, Devine GJ. Pyriproxyfen and house flies (Diptera: Muscidae): effects of direct exposure and autodissemination to larval habitats. J Med Entomol. 2012;49(3):606-613. Medline

28. Sumitomo Chemical. Sumilarv 0.5G. Sumitomo Chemical Website. http:// sumivector.com/larvicides/sumilarv. Accessed 21 March 2019.

29. Kamimura K, Arakawa R. Field evaluation of an insect growth regulator, pyriproxyfen, against Culex pipiens pallens and Culex tritaeniorhynchus. Med Entomol Zool. 1991;42(3):249-254. CrossRef

30. Yapabandara AMGM, Curtis CF. Laboratory and field comparisons of pyriproxyfen, polystyrene beads and other larvicidal methods against malaria vectors in Sri Lanka. Acta Trop. 2002;81(3):211-223. CrossRef. Medline

31. Kamal $H$, Khater $E$. The biological effects of the insect growth regulators; pyriproxyfen and diflubenzuron on the mosquito Aedes aegypti. J Egypt Soc Parasitol. 2010;40:565-574. Medline

32. Itoh $T$, Kawada $H$, Abe A, Eshita $Y$, Rongsriyam $Y$, Igarashi A. Utilization of bloodfed females of Aedes aegypti as a vehicle for the transfer of the insect growth regulator pyriproxyfen to larval habitats. J Am Mosq Control Assoc. 1994; 10(3):344-347. Medline

33. Sihuincha $M$, Zamora-Perea E, Orellana-Rios W, et al. Potential use of pyriproxyfen for control of Aedes aegypti (Diptera: Culicidae) in lquitos, Peru. $J$ Med Entomol. 2005;42(4):620-630. Medline

34. Vythilingam I, Luz BM, Hanni R, Beng TS, Huat TC. Laboratory and field evaluation of the insect growth regulator pyriproxyfen (Sumilarv $0.5 \mathrm{G}$ ) against dengue vectors. J Am Mosq Control Assoc. 2005;21(3):296-300. CrossRef. Medline

35. World Health Organization (WHO). Pyriproxyfen in Drinking-Water: Use for Vector Control in Drinking-Water Sources and Containers-Background Document for Development of WHO Guidelines for Drinking-Water Quality. Geneva: WHO; 2008. https://www.who.int/water_sanitation_health/dwq/ chemicals/pyriproxyfenvector.pdf. Accessed 21 March 2019.

36. Schaefer C, Miura T. Chemical persistence and effects of S-31 183, 2-[1-methyl-2-(4-phenoxyphenoxy) ethoxy] pyridine, on aquatic organisms in field tests. J Econ Entomol. 1990;83(5):1768-1776. CrossRef

37. Schaefer C, Dupras E, Mulligan F. Studies on the environmental persistence of S-31183 (pyriproxyfen): adsorption onto organic matter and potential for leaching through soil. Ecotoxicol Environ Saf. 1991;21(2):207-214. CrossRef. Medline

38. Mazigo E, Kidima W, Myamba J, Kweka EJ. The impact of Anopheles gambiae egg storage for mass rearing and production success. Malaria J. 2019;18:52. CrossRef. Medline 
39. Balestrino F, Benedict $M$, Gilles J. A new larval tray and rack system for improved mosquito mass rearing. J Med Entomol. 2012;49(3):595-605. Medline

40. World Health Organization (WHO). Guidelines for Laboratory and Field Testing of Mosquito Larvicides. Geneva: WHO;2005. https://apps.who.int/ iris/handle/10665/69101. Accessed 21 March 2019.

41. Okech BA, Gouagna LC, Killeen GF, et al. Influence of sugar availability and indoor microclimate on survival of Anopheles gambiae (Diptera: Culicidae) under semifield conditions in western Kenya. J Medical Entomol. 2003;40(5):657-663. Medline

42. Kweka E, Zhou G, Beilhe L, et al. Effects of co-habitation between Anopheles gambiae s.s. and Culex quinquefasciatus aquatic stages on life history traits. Parasit Vectors. 2012;5:33. CrossRef. Medline

43. Mbare O, Lindsay SW, Fillinger U. Dose-response tests and semi-field evalvation of lethal and sub-lethal effects of slow release pyriproxyfen granules (Sumilarv ${ }^{\circledR} 0.5 \mathrm{G}$ ) for the control of the malaria vectors Anopheles gambiae sensu lato. Malar J. 2013;12:94. CrossRef. Medline

44. Becker N, Rettich F. Protocol for the introduction of new Bacillus thuringiensis israelensis products into the routine mosquito control program in Germany. J Am Mosq Control Assoc. 1994;10(4):527-533. Medline

45. Kawada $H$, Shono $Y$, Ito $T$, Abe $Y$. Laboratory evaluation of insect growth regulators against several species of anopheline mosquitoes. Jpn J Sanit Zool. 1993;44(4):349-353. CrossRef

46. Andrighetti MTM, Cerone F, Rigueti M, Galvani KC, Macoris MdLdG. Effect of pyriproxyfen in Aedes aegypti populations with different levels of susceptibility to the organophosphate temephos. Dengue Bull. 2008;32:186-198.

47. Hatakoshi M, Kawada H, Nishida S, Kisida H, Nakayama I. Laboratory evaluation of 2-[1-methyl-2-(4-phenoxyphenoxy)-ethoxy] pyridine against larvae of mosquitoes and housefly. Jpn J Sanit Zool. 1987;38(4):271-274. CrossRef

48. Caputo B, lenco A, Cianci $D$, et al. The "auto-dissemination" approach: a novel concept to fight Aedes albopictus in urban areas. PLoS Negl Trop Dis. 2012;6(8):e1793. CrossRef. Medline

49. Al-Sarar AS, Al-Shahrani D, Bayoumi AE, Abobakr Y, Hussein HI. Laboratory and field evaluation of some chemical and biological larvicides against Culex spp. (Diptera: Culicidae) immature stages. Int J Agr Biol. 2011;13:115-119.

50. Nayar JK, Ali A, Zaim M. Effectiveness and residual activity comparison of granular formulations of insect growth regulators pyriproxyfen and s-methoprene against Florida mosquitoes in laboratory and outdoor conditions. J Am Mosq Control Assoc. 2002;18(3):196-201. Medline

51. Lima EP, Goulart MOF, Neto MLR. Meta-analysis of studies on chemical, physical and biological agents in the control of Aedes aegypti. BMC Public Health. 2015;15:858. CrossRef. Medline

52. Mulligan FS 3rd, Schaefer CH. Efficacy of a juvenile hormone mimic, pyriproxyfen (S-31183), for mosquito control in dairy wastewater lagoons. J Am Mosq Control Assoc. 1990;6(1):89-92. Medline

53. Kweka EJ, Zhou G, Munga S, et al. Anopheline larval habitats seasonality and species distribution: a prerequisite for effective targeted larval habitats control programmes. PLoS One. 2012;7(12):e52084. CrossRef. Medline

54. Kweka EJ, Zhou G, Lee MC, et al. Evaluation of two methods of estimating larval habitat productivity in western Kenya highlands. Parasit Vectors. 2011;4:110. CrossRef. Medline

55. Gimnig JE, Ombok M, Kamau L, Hawley WA. Characteristics of larval anopheline (Diptera: Culicidae) habitats in Western Kenya. J Med Entomol. 2001;38(2):282-288. Medline

56. Mireji PO, Keating J, Hassanali A, et al. Heavy metals in mosquito larval habitats in urban Kisumu and Malindi, Kenya, and their impact. Ecotoxicol Environ Saf. 2008;70(1):147-153. CrossRef. Medline
57. Kweka EJ, Munga S, Himeidan Y, Githeko AK, Yan G. Assessment of mosquito larval productivity among different land use types for targeted malaria vector control in the western Kenya highlands. Parasit Vectors. 2015;8:356. CrossRef. Medline

58. Munga S, Vulule J, Kweka EJ. Response of Anopheles gambiae s.I. (Diptera: Culicidae) to larval habitat age in western Kenya highlands. Parasit Vectors. 2013;6:13. CrossRef. Medline

59. Msangi S, Lyatuu E, Kweka EJ. Field and laboratory evaluation of bioefficacy of an insect growth regulator (Dimilin) as a larvicide against mosquito and housefly larvae. J Trop Med. 2011;2011:394541. CrossRef. Medline

60. Loh $\mathrm{P}$, Yap $\mathrm{H}$. Laboratory studies on the efficacy and sublethal effects of an insect growth regulator, pyriproxyfen (S-31183) against Aedes aegypti (Linnaeus). Trop Biomed. 1989;6:7-12.

61. Judson CL, de Lumen HZ. Some effects of juvenile hormone and analogues on ovarian follicles of the mosquito Aedes aegypti (Diptera: Culicidae). J Med Entomol. 1976;13:197-201. Medline

62. Fournet F, Sannier C, Monteny N. Effects of the insect growth regulators OMS 2017 and diflubenzuron on the reproductive potential of Aedes aegypti. J Am Mosq Control Assoc . 1993;9(4):426-430. Medline

63. Karatolos N, Williamson MS, Denholm I, Gorman K, Ffrench-Constant RH, Bass C. Over-expression of a cytochrome P450 is associated with resistance to pyriproxyfen in the greenhouse whitefly Trialeurodes vaporariorum. PLoS One. 2012;7(2):e31077. CrossRef. Medline

64. Mahande A, Dusfour I, Matias J, Kweka E. Knockdown resistance, Rdl alleles, and the annual entomological Inoculation rate of wild mosquito populations from Lower Moshi, Northern Tanzania. J Glob Infect Dis. 2012;4(2):1 14-119. CrossRef. Medline

65. Hamid PH, Prastowo J, Widyasari A, Taubert A, Hermosilla C. Knockdown resistance $(\mathrm{kdr})$ of the voltage-gated sodium channel gene of Aedes aegypti population in Denpasar, Bali, Indonesia. Parasit Vectors. 2017;10:283. CrossRef. Medline

66. Du M-H, Yan Z-W, Hao YJ, et al. Suppression of Laccase 2 severely impairs cuticle tanning and pathogen resistance during the pupal metamorphosis of Anopheles sinensis (Diptera: Culicidae). Parasit Vectors. 2017;10:171. CrossRef. Medline

\section{Peer Reviewed}

Competing Interests: This study was funded by the Sumitomo Chemical Co., Ltd., Tokyo, Japan. The funder had no role in data collection, data analysis, results interpretation, or the conclusions derived from this study. There are no other potential conflicts of interest to declare related to this study.

Received: 15 Jan 2019; Accepted: 15 Mar 2019

Cite this article as: Kweka EJ, Mahande AM, Msangi S, et al. Biological Activity of Sumilarv $0.5 \mathrm{G}$ against Anopheles gambiae sensu stricto and Anopheles arabiensis in Northern Tanzania. E Afr Sci. 2019;1(1):35-42. http://doi.org/10.24248/ EASci-D-19-00001.

(C) Kweka et al. This is an open-access article distributed under the terms of the Creative Commons Attribution License, which permits unrestricted use, distribution, and reproduction in any medium, provided the original author and source are properly cited. To view a copy of the license, visit http://creativecommons. org/licenses/by/4.0/. When linking to this article, please use the following permanent link: http://doi.org/10.24248/EASci-D-19-00001. 